\title{
Family Conditions and the Accessibility of Online Education: The Digital Divide and Mediating Factors
}

\author{
Jiafeng Gu 10 \\ Institute of Social Science Survey, Peking University, Beijing 100871, China; isssgujf@pku.edu.cn
}

\begin{abstract}
This study is an exploration of the digital divide between urban and rural areas, and it was conducted to assess the impact of the minimum living guarantee system on online education in China. The results of the research showed that $83.38 \%$ of students in low-income families have been able to participate in online education at home during the pandemic, while $16.62 \%$ of students in low-income families have been unable to do so. The absence of computers, smartphones, and broadband Internet access in low-income households reduces the likelihood of children being able to participate in online education at home. In terms of accessing online education at home, students from urban areas have obvious advantages over those from rural ones, and students from minimum living guarantee families have obvious advantages over those from marginal minimum living guarantee ones. This study also showed that the presence of online education-related amenities, including computers, smartphones, and Internet access, mediates the relationship between the subsistence allowance system, Hukou, and accessibility of online education. To address this issue, this paper includes suggestions for bridging the digital divide in online education.
\end{abstract}

Keywords: online education; digital divide; COVID-19 pandemic; mediation effect; China

Citation: Gu, J. Family Conditions and the Accessibility of Online Education: The Digital Divide and Mediating Factors. Sustainability 2021, 13, 8590. https://doi.org/10.3390/ su13158590

Academic Editors: Łukasz Tomczyk and Laura Fedeli

Received: 7 July 2021

Accepted: 29 July 2021

Published: 1 August 2021

Publisher's Note: MDPI stays neutral with regard to jurisdictional claims in published maps and institutional affiliations.

Copyright: (C) 2021 by the author. Licensee MDPI, Basel, Switzerland. This article is an open access article distributed under the terms and conditions of the Creative Commons Attribution (CC BY) license (https:// creativecommons.org/licenses/by/ $4.0 /)$.

\section{Introduction}

At the beginning of 2020, the COVID-19 pandemic spread rapidly, affecting more than 200 countries and regions. While the pandemic has affected the economic and social lives of people worldwide, it has also severely restricted education and instruction across the globe. According to UNESCO reports released in March 2020, about 102 countries and regions worldwide suspended classroom instruction, and more than 850 million children, or half of the world's student population, could no longer attend school due to the outbreak of the pandemic [1]. Online education has become the safest choice for providing instruction during the pandemic, and various countries have taken active measures to promote the development of remote instructional methods [2,3]. However, the inequities that affect access to online education have also become more prominent because of the pandemic [4]. In fact, the visibility of the digital divide in online education has increased more during the COVID-19 pandemic than could previously have been imagined [5]. The "digital divide" is the information gap that exists between individuals, groups, and nations, which is due to the unequal allocation of Information and Communication Technologies (ICT) access and use [5-7]. How to bridge the digital divide in online education and ensure fair and equal access to high-quality instruction is a problem faced by countries worldwide [8].

As one of the first countries to be hit by the pandemic, China actively responded to the challenge posed to education and instruction [9]. On 21 January 2020, China's Ministry of Education issued a notice requesting that pandemic prevention and control efforts be reflected within the education system by delaying the start of the 2020 spring semester and calling on primary and secondary schools to use online platforms to "suspend classes without stopping teaching and without stopping school". This constituted the most substantial online teaching initiative in human history and required tens of millions of students to complete the conversion from offline to online learning virtually overnight. 
Online education has thus received unprecedented attention, replacing traditional offline classrooms as the main learning context for students during the pandemic [10]. Teachers and students no longer meet in person as usual [11]. Regardless of whether they were willing or prepared to do so, students were forced to adapt quickly to this change in instructional delivery. Online education has partially compensated for the lack of classroom instruction during the crisis. However, the deficiencies in the network environments and hardware to which low-income rural families have access merit continued attention.

This study was based on survey data from 2401 low-income families in China and was conducted with the aim of assessing the accessibility of online education to students from such families during the pandemic; subsequently, the impact of the digital divide is highlighted. The "first-level digital divide" remains a problem even in technologically advanced countries [12]. The term refers to the gap in ownership of such technologies and the lack of information and communication-related technology and tools among some segments of the population, and it is sometimes also referred to as the "first-generation digital divide". Richard [6] proposed that the term "digital divide" should be used to refer to differences between various social classes' opportunities to access information and communication-related technologies. This divide requires continued attention because, in addition to considering whether a student has an Internet connection, differences in hardware access must be considered [13]. The research questions are focused on probing the first-level digital divide in terms of access to online education. The first level pertains to whether the digital infrastructure in low-income households is sufficient, including the smart terminals and broadband networks required for online education, and whether access to it is equitable. On this basis, further research was conducted on whether the related amenities, such as computers, smartphones, and Internet access, mediated the impact of the urban/rural divide and the minimum living guarantee policy on the accessibility of online education.

\section{Literature Review and Hypothesis Development}

Throughout the pandemic, the massive application of online learning practices has fully exposed the imbalances in the provision of online education to students in various regions, urban and rural areas, and schools, which are manifested in obvious differences in communications infrastructure and digital education resources across China $[9,14]$. In addition, the importance of a student's family environment in online learning outcomes has become increasingly prominent [15]. A student's home environment has a decisive impact on the effects of online learning programs. The hardware necessary for engaging in online learning activities is mainly provided by students' families. The great disparities forming the digital divide have highlighted the imbalances between students' families in terms of access to online education opportunities. The large-scale implementation of online instruction during the pandemic has provided us with a good opportunity to evaluate the status quo of online education and its impact on families in urban and rural areas in light of the digital divide in China. Such research not only holds the potential to become an important guiding force in helping China to bridge the digital divide in online education; it can also provide a useful frame of reference for countries seeking to promote equal access to education through the development of online education delivery methods that are equitable [16].

Online education has developed rapidly with the increased use of the Internet and the widespread availability of personal computers [17]. E-learning activities can be carried out regardless of differentials in time and space, and the scope of online education has thus expanded [18]. The viability of online education is restricted by many objective family circumstances, however. Students receive online education at home, and household conditions are important factors affecting the outcomes of online education [19]. Students must access online education at home, so various amenities, including computers, smart phones, and access to a broadband network, are necessities [20]. Families in various socioeconomic circumstances tend to have different levels of access to such amenities, which inevitably 
affects students' access to digital resources and causes a digital divide to develop between families with personal computers and those that cannot afford them [21]. Reflecting a typical mobile learning method, smartphone terminals have enhanced the convenience and accessibility of mobile online education [22]. When students lack personal computers and smartphones, it is difficult for them to participate in online education at home without external help from neighbors, communities, and local government [20]. In the context of online learning at home, the previously mentioned smart terminal equipment typically requires broadband Internet access [23]. Thus, the availability of a broadband Internet connection and the implementation of online education initiatives are complementary [24]. Given the parameters of the discussion outlined above, the following three hypotheses are proposed:

Hypothesis 1. Having a personal computer at home has a positive impact on a student's access to online education.

Hypothesis 2. Having a smartphone at home has a positive impact on a student's access to online education.

Hypothesis 3. Having a broadband Internet connection at home has a positive impact on a student's access to online education.

With the continuous development of the economy and the gradual deepening of digital transformations, the digital divide that plagues disadvantaged groups, such as lowincome families, has become increasingly obvious [25]. China has established a minimum living guarantee system to guarantee a minimum standard of living for the lowest-income families [26]. "Minimum living guarantee" families are those headed by parents whose monthly income is lower than the standard local minimum living allowance due to physical disability or illness. These parents can enjoy a national minimum living guarantee subsidy, and the government provides educational subsidies to address the issue of funding their children's education. The digital gap between families in urban and rural areas can further enlarge the differences in families' ability to invest in educational capital, exacerbating gaps in educational opportunities and achievements and precipitating the consolidation of social classes [27]. In the construction of digital infrastructure, there is often a large divide between urban and rural areas [28]. Compared to urban areas, rural ones tend to lag in constructing digital infrastructure [29]. The dropout rates of rural distance students are higher than those of their urban counterparts [30]. The digital divide between urban and rural areas has further expanded during the pandemic, causing online education to face unprecedented challenges [5]. The urban-rural divide can be measured by Hukou [31]. Hukou, also known as "household registration," refers to a legal document prepared by the state administrative agency in charge of household registration to record and retain basic information about the composition of households [32]. There is a negative correlation between agricultural Hukou and access to computers, learning software, and the Internet, which restricts students with agricultural Hukou from receiving online education at home [33]. Given the discussion described above, the following two hypotheses are proposed:

Hypothesis 4. The presence of a subsistence allowance has a positive impact on the accessibility of online education.

Hypothesis 5. The agricultural Hukou has a negative impact on the accessibility of online education.

The presence of a subsistence allowance has a positive impact on the accessibility of online education because it results in improved access to the amenities required to participate in online education at home [20]. Minimum living guarantee families that receive special funding for education from the government can use the money they receive to purchase the equipment required for online education and pay for access to broadband 
networks [34]. Therefore, the presence of online education-related amenities, including computers, smartphones, and an Internet connection, can play a mediating role in the impact of the subsistence allowance system on the provision of online education. The digital divide between urban and rural areas can lead to gaps in access to the amenities required for online education, reflecting disparities in the accessibility of online education to students from urban and rural families [28,29]. Therefore, such amenities, including computers, smartphones, and an Internet connection, can play a mediating role in the impact of the Hukou system on online education outcomes. Given the discussion outlined above, the following two hypotheses are proposed:

Hypothesis 6. The presence of online education-related amenities, including computers, smartphones, and an Internet connection, mediates the relationship between the presence of subsistence allowance systems and the accessibility of online education.

Hypothesis 7. The presence of online education-related amenities, including computers, smartphones, and an Internet connection, mediates the relationship between Hukou and accessibility of online education.

Figure 1 is a graphical representation of the proposed theoretical model and the hypotheses to be tested.

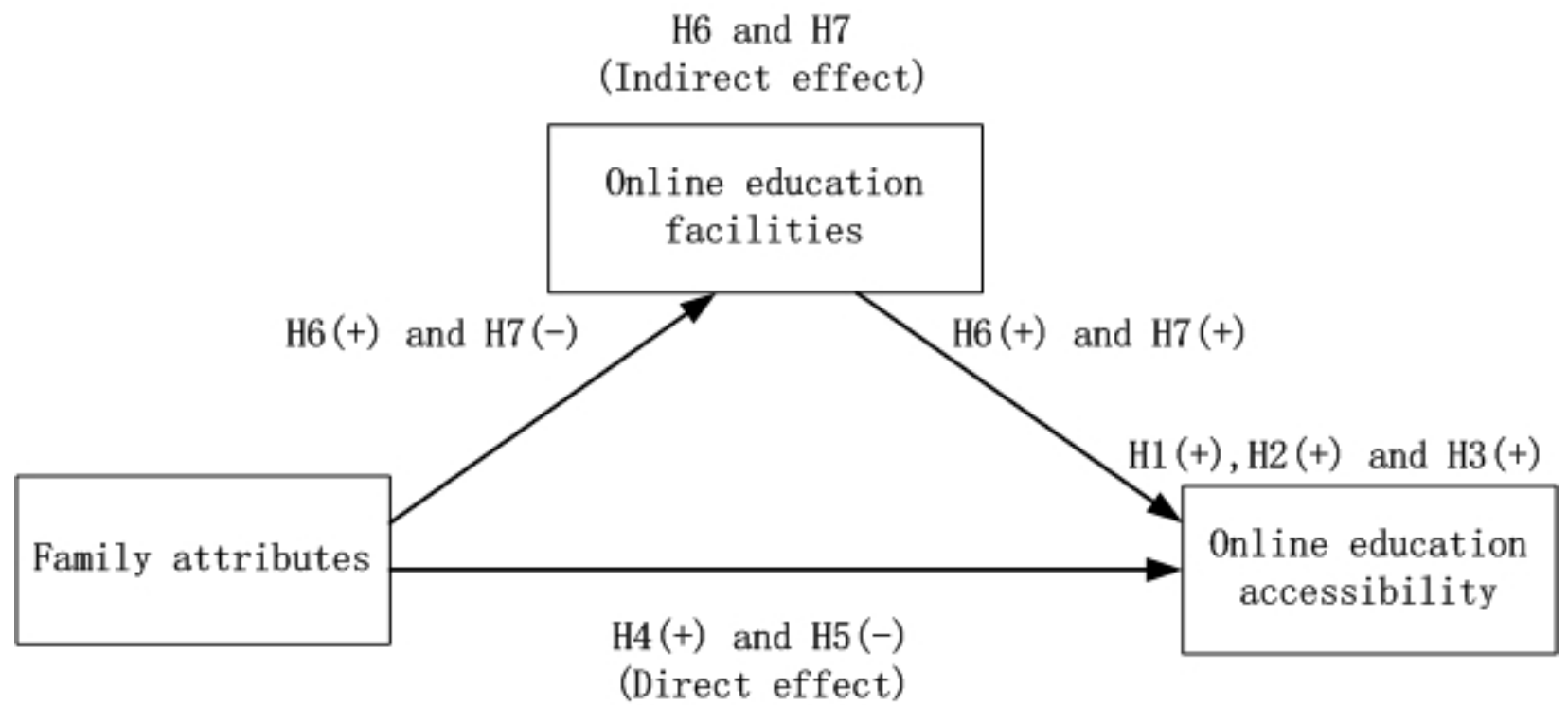

Figure 1. Theoretical model with hypotheses.

\section{Sample, Variables, and Method}

\subsection{Sample}

The data used in this study were obtained from a comprehensive survey of Chinese low-income families in 2020, which was designed by the Ministry of Civil Affairs of the People's Republic of China and conducted by the Institute of Social Science Study (ISSS) at Peking University. The survey sample included low-income households such as urban and rural minimum living guarantee families and marginal minimum living guarantee families. For the majority of low-income families in China, an important subsistence allowance comes from China's Minimum Living Standard Guarantee System [35]. Households with family per capita income lower than local minimum living standard guarantee thresholds can apply for China's Minimum Living Standard Guarantee System [36]. The families that receive this allowance are the minimum living guarantee families. The marginal minimum living guarantee families are families whose per capita income is slightly higher than the 
minimum living standard guarantee threshold and cannot be covered by the minimum living guarantee system [37].

The aim was to objectively assess the economic status of the families in terms of the difficulties they faced, the reasons for their poverty, and their needs in terms of social policies. The survey was conducted via telephone through computer-assisted telephone interviews (CATIs). Questions related to the COVID-19 pandemic were added to the 2020 questionnaire to assess the impact of the pandemic on low-income families and included items regarding how children from low-income families accessed online education at home during the pandemic. In this survey sample, there were 2683 households with children, of which 2401 included children receiving compulsory education. Therefore, these 2401 households were included in the final sample for this study.

\subsection{Measurement}

The respondents were asked the following question: "During the 2020 COVID-19 pandemic, were there any children in your family taking online classes?" The aim of asking this question was to measure the distribution of dependent variables. A positive answer was defined as 1 , and a negative answer was defined as 0 .

In this study, a set of two-category variables related to the hardware required for online education was used to measure the first level of the digital divide in online education. This set included whether the student had access to a personal computer, smartphone, and broadband Internet connection at home. For example, the respondents were asked the following question: "Do you currently have the following item (personal computer) in your home?" A positive answer was defined as 1 , and a negative answer was defined as 0 . The internal consistency had a Cronbach $\alpha$ of 0.86 . The test-retest reliability of those measurements had a weighted $\kappa$ of 0.76 . In addition, before this survey, three rounds of pilot surveys were conducted to test the measurement validity of the questionnaire. The final questionnaire was formed to ensure the validity of the questionnaire by deleting the questions with low measurement validity.

To account for individual families' differences, we considered the variable "subsistence allowance". In this study, the subsistence allowance had been defined operationally as the minimum living guarantee allowance. If a family received a subsistence allowance and was a minimum living guarantee family, it was defined as 1 ; otherwise, it was defined as 0 . The Hukou system is a mandatory household registration system in China that assigns an individual either an urban/non-agricultural Hukou or a rural/agricultural Hukou based on one's birthplace [38]. Although the "floating population" exists, which is defined as those whose usual places of residence are in urban areas but who still hold agricultural Hukou or those whose usual places of residence are in rural areas but who still hold nonagricultural Hukou [39]. However, academics are still accustomed to using non-agricultural Hukou/agricultural Hukou to distinguish urban and rural samples [40,41]. According to this convention, to account for urban and rural differences, we considered the variable Hukou (agricultural and non-agricultural).

\subsection{Statistical Modeling}

We used a chi-square analysis and t-tests to describe the binary correlation between the influencing factors and access to online education. In this study, a multivariate logistic regression analysis was conducted to test each hypothesis in the theoretical model using STATA 15. The significance level was set at $\alpha=0.05$, and all the tests were two-tailed.

First, the following logistic regression model was used to assess the impact of online education-related amenities at home and individual family attributes on the accessibility of online education:

$$
\text { Logit } P(Y=1 \mid X)=\ln \frac{P(Y=1 \mid X)}{1-P(Y=1 \mid X)}=\alpha_{j}+\beta X+e
$$


Here, $Y$ is the accessibility of online education to a student and is a categorical variable of 0 or 1 . A value of 1 means that a student can access online education at home, and 0 means that they cannot do so. $X$ includes five explanatory variables: whether there is a personal computer at home, whether there is a smartphone at home, whether there is access to a broadband network at home, whether a household qualifies as low-income, and whether a household is part of a rural agricultural Hukou. The five explanatory variables were all based on categorical variables of 0 and 1.

On this basis, we further examined whether family attributes would affect the accessibility of online education through the presence of online education-related amenities. According to the mediating variable test method proposed by Baron and Kenny [42], when the dependent variable is a categorical variable, the logistic model can be used to perform an empirical test of the mediating variable through the following three steps:

$$
\begin{gathered}
Y^{\prime}=\operatorname{Logit} P(Y=1 \mid X)=\ln \frac{P(Y=1 \mid X)}{1-P(Y=1 \mid X)}=i_{1 j}+c X+e_{1} \\
M=\operatorname{Logit} P(M=1 \mid X)=\ln \frac{P(M=1 \mid X)}{1-P(M=1 \mid X)}=i_{2 j}+a X+e_{M} \\
Y^{\prime \prime}=\text { Logit } P(Y=1 \mid M, X)=\ln \frac{P(Y=1 \mid M, X)}{1-P(Y=1 \mid M, X)}=i_{3 j}+c^{\prime} X+b M+e_{y}
\end{gathered}
$$

This study is an examination of whether personal computers, smartphones, and access to a broadband network are mediating variables that affect the accessibility of online education in low-income and rural households. Therefore, in Formulas (2)-(4), $X$ includes the two independent variables indicating whether a household is low-income or agricultural Hukou household. $M$ is the mediating variable, pertaining to items such as whether there is a personal computer at home, whether there is a smartphone at home, and whether there is access to a broadband network at home. $Y^{\prime}$ and $Y^{\prime \prime}$ refer to the same variable, namely whether online education is accessible. In the empirical test, $X$ contains two variables, namely, minimum living guarantee households and agricultural Hukou households, which correspond to $x_{1}$ and $x_{2}$. Correspondingly, the regression coefficients in Formula (3) are $a_{1}$ and $a_{2}$, respectively, and the regression coefficients in Formula (4) are $c_{1}^{\prime}$ and $c_{2}^{\prime}$, respectively.

\section{Results}

The online education results of the respondents are presented in Table 1. In 2020, $83.38 \%$ of the students in the sample participated in online education at home $(\mathrm{N}=2002)$, while $16.62 \%$ did not do so $(\mathrm{N}=399)$.

In terms of physical equipment, the proportion of households that owned personal computers and smartphones was $23.7 \%$ and $88.90 \%$, respectively, while $62.8 \%$ of the households surveyed had broadband Internet access. A total of $55.9 \%$ of the households received subsistence allowances, and $71.9 \%$ of the households belonged to the agricultural Hukou category.

Table 1 shows a combination of statistics related to access to online education and household-level characteristics in 2020. The binary crosstabs show that the students who reported being able to receive online education were more likely to come from families that had access to personal computers, smartphones, and broadband Internet access. It seems that Hukou status had an impact on the accessibility of online education, while the presence of a subsistence allowance did not.

Table 2 presents the results of the multivariate logistic regression analysis. The Cox and Snell R square values were 0.143 , and the $\rho^{2}$ (Nagelberke) was 0.189 . The value of the $-2 \log$ likelihood was 2026.99. The chi-square value was 132.84 , which was significant $(p=0.000)$. 
Table 1. Distribution and chi-square of general characteristics.

\begin{tabular}{|c|c|c|c|c|c|}
\hline \multirow{2}{*}{\multicolumn{2}{|c|}{ Classification }} & \multirow{2}{*}{$\begin{array}{c}\text { Participants } \\
(\mathbf{N}=1565) \\
\text { N (\%) }\end{array}$} & \multicolumn{2}{|c|}{ Online Education or Not } & \multirow[t]{2}{*}{$\chi^{2}(p)$} \\
\hline & & & $\begin{array}{c}\text { Online Education } \\
\text { N (\%) }\end{array}$ & $\begin{array}{l}\text { No Online } \\
\text { Education } \\
\text { N (\%) }\end{array}$ & \\
\hline \multirow{2}{*}{ Computer } & Yes & $569(23.7)$ & $520(26.0)$ & $49(12.3)$ & \multirow{2}{*}{$\begin{array}{c}34.499 * * * \\
(0.000)\end{array}$} \\
\hline & No & $1832(76.3)$ & $1482(74.0)$ & $350(87.7)$ & \\
\hline \multirow{2}{*}{ Smartphone } & Yes & $2115(88.09)$ & $1802(90.0)$ & $313(78.4)$ & \multirow{2}{*}{$\begin{array}{l}42.399 * * * \\
(0.000)\end{array}$} \\
\hline & No & $286(11.91)$ & $200(10.0)$ & $86(21.6)$ & \\
\hline \multirow{2}{*}{ Internet } & Yes & $1507(62.8)$ & $1324(66.1)$ & $183(45.9)$ & \multirow{2}{*}{$\begin{array}{l}58.486^{* * * *} \\
\quad(0.000)\end{array}$} \\
\hline & No & $894(37.2)$ & $678(33.9)$ & $216(54.1)$ & \\
\hline \multirow{2}{*}{$\begin{array}{l}\text { Subsistence } \\
\text { Allowance }\end{array}$} & Yes & $1342(55.9)$ & $889(44.4)$ & $170(42.6)$ & \multirow{2}{*}{$\begin{array}{c}0.437 \\
(0.000)\end{array}$} \\
\hline & No & $1059(44.1)$ & $1113(55.6)$ & $229(57.4)$ & \\
\hline \multirow{2}{*}{ Hukou } & Agricultural & $1726(71.9)$ & $1382(69.0)$ & $344(86.2)$ & \multirow{2}{*}{$\begin{array}{l}48.614^{* * * *} \\
(0.000)\end{array}$} \\
\hline & Non-agricultural & $675(28.1)$ & $620(31.0)$ & $55(13.8)$ & \\
\hline \multirow{2}{*}{ Online Education } & Yes & $2002(83.38)$ & - & - & - \\
\hline & No & $399(16.62)$ & - & - & - \\
\hline
\end{tabular}

Table 2. Multivariable logistic regression analysis.

\begin{tabular}{cccc}
\hline Characteristics & Online Education \\
& Odds Ratio & 95\% CI & $p$-Value \\
\hline Computer: yes vs. no & $1.639^{* * * *}$ & $1.171-2.292$ & 0.004 \\
Smartphone: yes vs. no & $1.821^{* * *}$ & $1.339-2.475$ & 0.000 \\
Internet: yes vs. no & $1.752^{* * *}$ & $1.373-2.233$ & 0.000 \\
Subsistence Allowance: yes vs. no & $1.403^{* * *}$ & $1.117-1.761$ & 0.004 \\
Hukou: agricultural vs. non-agricultural & $0.387^{* * *}$ & $0.284-0.528$ & 0.000 \\
Constant & $3.66^{* * *}$ & $2.499-5.36$ & 0.000 \\
\hline & Note: ${ }^{* * *}$ significant at $1 \%$.
\end{tabular}

The results of this analysis show that in 2020, students in families that reported owning personal computers were more likely to report having access to online education than those that did not have access to such technology (OR $=1.639 ; 95 \%$ CI: 1.171-2.292). Thus, Hypothesis 1 was confirmed. Students in families that reported owning smartphones were more likely to have access to online education than those in families that did not own smartphones (OR $=1.821 ; 95 \%$ CI: 1.339-2.475). Thus, Hypothesis 2 was confirmed. Students in families with access to broadband networks were more likely to have access to online education than families without it ( $\mathrm{OR}=1.752 ; 95 \% \mathrm{CI}: 1.373-2.233)$. As such, Hypothesis 3 was also confirmed.

In addition, the students in families receiving subsistence allowances were more likely to have access to online education than those in families that did not receive an allowance $(\mathrm{OR}=1.403 ;$; $\%$ CI: 1.117-1.761). Thus, Hypothesis 4 was confirmed. Students in families with agricultural Hukou status were less likely to have access to online education than those that belonged to the non-agricultural Hukou category ( $\mathrm{OR}=0.387 ; 95 \%$ CI: $0.284-0.528$ ). Thus, Hypothesis 5 was confirmed.

To test the impact of the subsistence allowance system and Hukou systems on access to online education and the mediating role of online education-related amenities, we conducted empirical testing implementing three rounds of mediating variable regressions. In the first round, whether there was a personal computer at home was used as a mediating variable to examine the impact of income and Hukou status on access to online education. 
In the second round, whether there was a smartphone in the home was used as a mediating variable to examine the impact of income and agricultural Hukou status on access to online education. In the third round, whether there was access to a broadband network at home was used as a mediating variable to examine the impact of income and Hukou status on access to online education. The results of the three rounds of intermediate variable tests are summarized in Table 3.

Table 3. Three rounds of mediating effect testing results.

\begin{tabular}{cccccccc}
\hline & $\begin{array}{c}\text { Mediating } \\
\text { Variable }\end{array}$ & $\boldsymbol{a}_{1}$ & $\boldsymbol{a}_{2}$ & $\boldsymbol{b}$ & $\boldsymbol{c}_{1}^{\prime}$ & $\boldsymbol{c}_{2}^{\prime}$ \\
\hline \multirow{2}{*}{ Round one } & \multirow{2}{*}{ Computer } & $1.64^{* * *}$ & $0.342^{* * *}$ & $2.108^{* * *}$ & $1.297^{* *}$ & $0.395^{* * *}$ \\
& & $1.335-2.015$ & $0.257-0.384$ & $1.525-2.916$ & $1.038-1.623$ & $0.29-0.538$ \\
\hline \multirow{2}{*}{ Round two } & \multirow{2}{*}{ Smartphone } & $1.678^{* * *}$ & $0.28^{* * *}$ & $2.525^{* * *}$ & $1.331^{* *}$ & $0.341^{* * *}$ \\
& & $1.303^{*}-2.6$ & $0.185-0.425$ & $1.896-3.361$ & $1.062-1.668$ & $0.252-0.463$ \\
\hline \multirow{2}{*}{ Round three } & \multirow{2}{*}{ Internet } & $1.396^{* * *}$ & $0.299^{* * *}$ & $2.237^{* * *}$ & $1.323^{* *}$ & $0.361^{* * *}$ \\
& & $1.179-1.654$ & $0.206-0.438$ & $1.793-2.79$ & $1.057-1.657$ & $0.265-0.489$ \\
\hline
\end{tabular}

Note: ${ }^{* *}$ and ${ }^{* * *}$ denote significance at the 0.05 and 0.01 levels, respectively. Further details on each model are contained in the Appendix A.

According to the results of the first round of regressions in Table 3, among low-income households, the probability of having a personal computer was 1.64 times that of nonsubsistence households (OR $=1.64 ; 95 \%$ : $1.335-2.015)$. The probability of agricultural Hukou households having a computer was only $34.2 \%$ of that of non-agricultural Hukou households (OR $=0.342 ; 95 \%$ : 0.257-0.384). In addition, when there was a computer mediation effect, in low-income households, the probability that children in subsistence households could access adequate resources for online education at home was 1.297 times that of non-subsistence households ( $\mathrm{OR}=1.297 ; 95 \%$ : $1.038-1.623)$, and the probability that children of agricultural Hukou households could access adequate resources for online education at home was only $39.5 \%$ of that of non-agricultural Hukou households $(\mathrm{OR}=0.395$; $95 \%$ : 0.29-0.538). Children with a personal computer at home were 2.108 times more likely to be able to participate in online education at home than children without one $(\mathrm{OR}=2.108$; 95\%: 1.525-2.916). The regression coefficients shown above are all significant, indicating that the availability of a personal computer has an intermediary effect on the impact of the minimum living guarantee and household registration on online education outcomes.

According to the results of the second round of regressions in Table 3, among lowincome households, the probability of having a smartphone was 1.678 times that of nonsubsistence households (OR $=1.678 ; 95 \%$ : 1.303-2.6). Agricultural Hukou households were only $28 \%$ more likely to own a smartphone than non-agricultural Hukou households $(\mathrm{OR}=0.28$; 95\%: 0.185-0.425). In addition, when there was an intermediary effect of smartphones, among low-income families, the average probability that children in subsistence households could access online education at home was 1.331 times that of non-subsistence households ( $\mathrm{OR}=1.331 ; 95 \%$ : $1.062-1.668)$, and the probability that children in agricultural Hukou households could access online education at home was only $34.1 \%$ of that of nonagricultural Hukou households (OR $=0.341 ; 95 \%$ : 0.252-0.463). Children with smartphones at home were 2.525 times more likely to be able to access online education at home than children without them $(\mathrm{OR}=2.525 ; 95 \%$ : 1.896-3.361). The regression coefficients mentioned above were all significant, indicating that the availability of a smartphone at home has a mediating effect on the impact of subsistence insurance and household registration on online education outcomes.

According to the results of the third round of regressions in Table 3, among low-income households, the probability of having access to a broadband network was 1.396 times that of non-subsistence households (OR = 1.396; 95\%: 1.179-1.654). Agricultural Hukou households were only $29.9 \%$ more likely to have access to a broadband network than their non-agricultural Hukou counterparts (OR = 0.299; 95\%: 0.206-0.438). In addition, when the mediating effect of access to a broadband network is taken into account, among low-income 
families, the average probability that children in subsistence households will have access to online education at home is 1.323 times that of non-subsistence households $(\mathrm{OR}=1.323$; 95\%: 1.057-1.657), and the probability that children in agricultural Hukou households will be able to access online education at home is only $36.1 \%$ of that of non-agricultural Hukou households $(\mathrm{OR}=0.361 ; 95 \%$ : 0.265-0.489). Children with broadband internet access at home were 2.237 times more likely to be able to participate in online education at home than children without it $(\mathrm{OR}=2.237 ; 95 \%: 1.793-2.79)$. The regression coefficients mentioned above are all significant, indicating that the presence of a broadband network at home has a mediating effect on the impact of household registration on access to online education in low-income households.

Thus, Hypotheses 6 and 7 were confirmed. These results show that, among lowincome families, the policy of providing a subsistence allowance provides a basic education guarantee that increases the probability of their children receiving online education at home, and it improves the accessibility of online education for such students by increasing the availability of digital amenities to low-income families. However, compared to their non-agricultural Hukou household counterparts, students of agricultural Hukou households are still at a significant disadvantage in terms of access to online education, and there are often insufficient online education-related amenities in rural students' homes, which limits the accessibility of online education in rural areas.

\section{Discussion}

The online learning context is different from the offline face-to-face classroom environment and requires a higher level of technological resources, such as smartphones, computers, and Internet access [43]. Students from middle-high-income families are less likely to encounter hardware-related constraints when engaging in online learning activities, while students from low-income families have relatively low hardware-ownership rates and may face a lack of devices and limited access to networks when attempting to access online education at home, thereby affecting the outcomes of online learning activities among low-income students. Students from low-income families are more likely to be excluded from online education activities because they cannot access the online instruction interface [20]. This research shows that students from low-income families and students who do not have computers, smartphones, or broadband Internet access at home are obviously at a disadvantage when it comes to accessing online learning at home. Ensuring that such students have access to personal computers, smartphones, and the Internet at home can increase their access to online education by $63.9 \%, 82.1 \%$, and $75.2 \%$, respectively. In other words, without the hardware required for participating in online education at home, the probability of students participating in such learning activities is significantly reduced and the children of such families may be excluded from the online education context.

According to data from the China Statistical Yearbook 2020, the rate of personal computer ownership in China in 2018 was $66.8 \%$, while, in this study, it was found that the rate in low-income households in 2020 was only 23.7\%. The data from the Report on China's Broadband Internet Penetration Status show that, in 2018, the rate of home broadband Internet access in China reached $86.1 \%$, while it was only $62.8 \%$ in low-income households in 2020. Regarding these two amenities, the rate in low-income families was significantly lower than the national average, which is obviously not conducive to encouraging equitable educational outcomes among students from low-income families. Fortunately, the rate of home smartphone ownership in low-income households was found to be relatively high, reaching $88.09 \%$. Students from low-income families can access online education activities through smartphones and $4 \mathrm{G}$ networks, which can somewhat compensate for the lack of personal computers and broadband network access in low-income families and can enable such children to access online learning at home. Of course, the effectiveness of online learning using smartphones and online learning using computers may be different. In this regard, experimental research can be conducted in the future to explore the differences in the effects of online learning by controlling different learning devices. 
Overall, low-income families have strikingly low rates of personal computer ownership and home Internet access. This research shows that there are obvious inequalities and disparities in terms of access to personal computers and the Internet, which can be seen as indicators of the digital divide, which has been fully exposed during the massive shift to online education during the pandemic $[5,20]$. In 2020, $16.62 \%$ of students from low-income families did not have the resources to access online education. Inequality in access to online education is an important metric for assessing the severity of the digital divide. For students from low-income families, inequality in access to online education persists at an alarming level in China. Although part of the discussion about online education has moved from ensuring access to enhancing quality, this shift is premature for low-income families. The question of how to guarantee access to online education at home remains a major challenge for these families.

To ensure that children from low-income families can enjoy equal access to a basic education, the Chinese government has implemented a minimum living guarantee system and has begun to provide education-related subsidies to such families. This research shows that education subsidies for minimum living guarantee families help students from such families access online education at home [26]. However, the minimum living guarantee system artificially divides low-income families into two categories: minimum living guarantee families and marginal minimum living guarantee ones. The monthly per capita income of marginal minimum living guarantee families is slightly higher than the local minimum living guarantee cutoff but lower than the minimum wage standard. As a result, such families cannot benefit from minimum living guarantee policies; do not have access to subsidies; and receive no assistance in terms of education, medical care, housing, and so forth. Therefore, this group may become an especially disadvantaged class whose actual living conditions are more impoverished than those of some minimum living guarantee families. In this study, it was found that the probability of students from marginal minimum living guarantee families being able to access online learning at home was $59.7 \%$ lower than for students from minimum living guarantee families, indicating that although all are low-income families in similar situations, there is already a digital divide in online education forming between the two groups of families.

This digital divide may have serious economic and social consequences for marginal minimum living guarantee families as information technology skills become increasingly important in the labor market. Past research and discussions have mainly focused on the digital divide in online education between students from rich and poor families, while the digital divide that also exists between various types of poor families has been ignored [44]. While the minimum living guarantee system protects the rights of students from minimum living guarantee families to enjoy access to online education activities, thereby narrowing the digital divide between them and students from wealthy families, it artificially widens the digital divide in online education between marginal minimum living guarantee families and minimum living guarantee ones. This kind of digital divide between impoverished families deserves the attention of all sectors of society. If measures cannot be implemented to close this digital divide, it is likely to evolve into a severe social divide in the future.

During the pandemic, most rural areas in China made full use of state-level resources and upgraded to high-quality online educational resources, ensured that various types of schools were organized at all levels to carry out online learning activities in an orderly manner, and arranged for high-quality teachers to record courses on digital TV stations and video platforms for use by students [9]. Such an approach is conducive to expanding the scope of knowledge acquisition for rural students, facilitates the sharing of high-quality educational resources, and compensates for the issue of insufficient resources provided by the families of rural students. However, because remote rural areas often have poor digital infrastructure, students cannot always carry out online learning activities in a timely or smooth manner, resulting in unequal access to educational resources and widening the urban-rural digital divide during the pandemic. This research shows that rural students 
have a $61.3 \%$ lower probability of possessing the resources to access online education at home than urban students, which places them at a significant disadvantage.

It appears that encouraging online learning at home may, in fact, fail to reduce the urban-rural education gap and instead widen it. As a countermeasure, the government should incorporate initiatives to improve online education among rural students in underdeveloped areas into the "education informatization" policy so that students in underdeveloped rural areas can enjoy high-quality educational resources. Precise interventions should also be made to help rural students and their families in underdeveloped areas by implementing appropriate measures and investing corresponding resources in improving the overall quality of online education. Concurrently, there is an urgent need to continue consolidating the network infrastructure, formulating network environment improvement plans, and improving the information service capabilities of underdeveloped rural areas.

This study has the following limitations. First, the composition of the semiprivate space for online education can be further investigated, and other elements that were not examined here may be affecting the gap between rural and urban students. Second, this study was based on cross-sectional data instead of panel data. Therefore, only correlations could be discussed, and causality could not be tested. Third, this study was focused on the accessibility of online education but the impact of family-level factors on the effectiveness of online education was not discussed. In addition, this research focuses on the impact of family conditions on the accessibility of online education at home, and does not explore the impact of smartphones, computers, and the Internet on the effectiveness of online education. With the development of surveillance capitalism and algorithmic discrimination, students receiving online education at home may also be exposed to risks such as addiction, manipulation, pornography, and narcissism [45]. Students in different family conditions may have significantly different risk tolerance in the face of these negative effects. These issues are worthy of further research and could provide meaningful directions for future work.

\section{Conclusions}

COVID-19 has been a catastrophe for the entire world. The universal transition to online education due to the COVID-19 pandemic has been an effective indicator of the opportunities and challenges that remain in ensuring equitable access to high-quality education. Worldwide, opportunities to access online education have varied dramatically between countries and individuals. This research shows that students from families without personal computers, smartphones, or Internet access in rural areas are more likely to have been unable to effectively access online learning at home during the COVID-19 pandemic. Moreover, the probability of students from marginal minimum living guarantee families being able to access online education at home was 59.7\% lower than for students from minimum living guarantee families, indicating that, even among impoverished families, there is a digital divide in online education. This kind of digital divide must be addressed by the government, as it is not advisable to bridge the digital divide by creating another one. Overall, these results are consistent with the data from emerging economies and confirm that the digital divide that persists in online education represents a large social challenge. The results reveal that the government must make further efforts to develop effective strategies for balancing social and educational opportunities among students, taking special care to ensure that students from low-income families in rural areas can enjoy equal access to online education at home.

When implementing social sustainable development strategies, the sustainable development of education should be given priority. Without educational equity, the sustainable development of education will be difficult to achieve. Online education platforms have rapidly grown in the past decade with the promise of reducing educational inequality through access to low-cost education for all. However, the inequality in online education is still shocking. This problem is especially prominent during the COVID-19 pandemic. This article focused on the impact of informational inequality across users of different family 
conditions in their differences in online education accessibility. On this basis, it proposed countermeasures to reduce inequality in online education. This is of great significance for realizing the sustainable development of education and the sustainable development of the entire society.

Funding: This research is funded by Peking University Education Big Data Project (2020YBC16).

Institutional Review Board Statement: Not applicable.

Informed Consent Statement: Not applicable.

Data Availability Statement: The data presented in this study are available on request from the corresponding author.

Acknowledgments: The authors gratefully acknowledge that this paper is one of the fruits of Peking University Education Big Data Project (2020YBC16). The authors would also like to thank the editor and three anonymous reviewers for their insightful comments and suggestions.

Conflicts of Interest: The authors declare no conflict of interest.

Appendix A. Three Rounds of Tests of Mediating Effects

Table A1. Round one: Personal computer access as the mediating variable.

\begin{tabular}{cccc}
\hline \multirow{2}{*}{ Characteristics } & Online Education & $\begin{array}{c}\text { Personal } \\
\text { Computer Access }\end{array}$ & Online Education \\
\cline { 2 - 4 } & Model 1 & Model 2 & Model 3 \\
\hline Personal computer access: yes vs. no & & & $2.108^{* * *}$ \\
Subsistence Allowance: yes vs. no & $1.241^{*}$ & $1.525-2.916)$ & $1.297^{* *}$ \\
Hukou: agricultural vs. non-agricultural & $(0.994-1.549)$ & $(1.335-2.015)$ & $\left(1.038^{* *}-1.623\right)$ \\
Constant & $0.342^{* * *}$ & $0.314^{* * *}$ & $0.395^{* * *}$ \\
& $(0.252-0.463)$ & $(0.257-0.384)$ & $(0.29-0.538)$ \\
& $10.604^{* * *}$ & $0.493^{* * *}$ & $\left(0.094^{* * *}\right.$ \\
\hline
\end{tabular}

Note: ${ }^{*}, * *$ and ${ }^{* * *}$ denote significance at the $0.1,0.05$, and 0.01 levels, respectively. Models 1,2 , and 3 correspond to Formulas (2)-(4), respectively.

Table A2. Round two: Smartphone access as the mediating variable.

\begin{tabular}{cccc}
\hline \multirow{2}{*}{ Characteristics } & Online Education & Smartphone Access & Online Education \\
\cline { 2 - 4 } & Model 4 & Model 5 & Model 6 \\
\hline Smartphone access: yes vs. no & & & $2.525^{* * *}$ \\
Subsistence Allowance: yes vs. no & $1.241^{*}$ & $1.696-3.361)$ \\
Hukou: agricultural vs. non-agricultural & $(0.994-1.549)$ & $(1.303-2.6)$ & $1.331^{* * *}$ \\
Constant & $0.342^{* * *}$ & $0.28^{* * *}$ & $(1.062-1.668)$ \\
& $(0.252-0.463)$ & $(0.185-0.425)$ & $0.341^{* * *}$ \\
& $10.604^{* * *}$ & $6.368^{* * *}$ & $(0.252-0.463)$ \\
& $(7.998-14.059)$ & $(4.744-8.547)$ & $(3.235-6.804)$ \\
\hline
\end{tabular}

Note: ${ }^{*}, *$ and ${ }^{* * *}$ denote significance at the $0.1,0.05$, and 0.01 levels, respectively. Models 4, 5, and 6 correspond to Formulas (2)-(4), respectively. 
Table A3. Round three: Internet access as the mediating variable.

\begin{tabular}{cccc}
\hline \multirow{2}{*}{ Characteristics } & Online Education & Internet Access & Online Education \\
\cline { 2 - 4 } & Model 7 & Model 8 & Model 9 \\
\hline Internet access: yes vs. no & & & $2.237^{* * *}$ \\
Subsistence Allowance: yes vs. no & $1.241^{*}$ & $1.793-2.79)$ & $1.323^{* *}$ \\
Hukou: agricultural vs. non-agricultural & $(0.994-1.549)$ & $(1.179-1.654)$ & $(1.057-1.657)$ \\
Constant & $0.342^{* * *}$ & $0.299^{* * *}$ & $0.361^{* * *}$ \\
& $(0.252-0.463)$ & $(0.206-0.438)$ & $(0.265-0.489)$ \\
& $10.604^{* * *}$ & $\left(1.824^{* * *}\right.$ & $6.289^{* * *}$ \\
\hline
\end{tabular}

Note: ${ }^{*}{ }^{* *}$ and ${ }^{* * *}$ denote significance at the $0.1,0.05$, and 0.01 levels, respectively. Models 7, 8, and 9 correspond to Formulas (2)-(4), respectively.

\section{References}

1. UNESCO. Half of World's Student Population Not Attending School: UNESCO Launches Global Coalition to Accelerate Deployment of Remote Learning Solutions. Available online: https://en.unesco.org/news/half-worlds-student-population-notattending-school-unesco-launches-global-coalition-accelerate (accessed on 19 March 2020).

2. McBurnie, C.; Adam, T.; Kaye, T. Is there learning continuity during the COVID-19 pandemic? A synthesis of the emerging evidence. J. Learn. Dev. 2020, 7, 485-493.

3. Xie, X.; Siau, K.; Nah, F.H. COVID-19 pandemic-Online education in the new normal and the next normal. J. Inf. Technol. Case Appl. Res. 2020, 22, 175-187. [CrossRef]

4. Yadav, D.K.; Singh, S.K.; Khan, Y.; Singh, R.; Yadav, S.L.; Shukla, R.K. Statistical assessment of online education during Covid-19 pandemic. In Advance Research Trends in Medical and Biological Sciences; Shukla, R.K., Singh, S.K., Yadav, D.K., Eds.; MKSES Publisher: Lucknow, India, 2021; pp. 95-114.

5. Qureshi, I.A.; Schaeffer, D.M.; Rasool, R.G.; Qureshi, S.N. E-learning challenges created by digital divide during COVID-19 pandemic: A case study of Pakistani university system. High Technol. Lett. 2020, 26, 734-745.

6. Richard, J. Understanding the digital divide. Prometheus 2001, 19, 333-336. [CrossRef]

7. Gray, J. Technology and social inclusion: Rethinking the digital divide. J. Econ. Issues 2004, 38, 294-296. [CrossRef]

8. Correia, A.-P. Healing the digital divide during the COVID-19 pandemic. Q. Rev. Distance Educ. 2020, $21,13-21$.

9. Xue, E.; Li, J.; Xu, L. Online education action for defeating COVID-19 in China: An analysis of the system, mechanism and mode. Educ. Philos. Theory 2020, 2,1-13. [CrossRef]

10. Sun, L.; Tang, Y.; Zuo, W. Coronavirus pushes education online. Nat. Mater. 2020, 19, 687. [CrossRef]

11. Cao, J.; Yang, T.; Lai, I.; Wu, J. Is online education more welcomed during COVID-19? An empirical study of social impact theory on online tutoring platforms. Int. J. Electr. Eng. Educ. 2021, 0020720920984001. [CrossRef]

12. Deursen, A.; Dijk, J. The first-level digital divide shifts from inequalities in physical access to inequalities in material access. New Media Soc. 2019, 21, 354-375. [CrossRef]

13. Gonzales, A. The contemporary US digital divide: From initial access to technology maintenance. Inf. Commun. Soc. 2016, 19, 234-248. [CrossRef]

14. Yao, J.; Rao, J.; Jiang, T.; Xiong, C. What role should teachers play in online teaching during the COVID-19 pandemic? Evidence from China. Sci. Insight Educ. Front. 2020, 5, 517-524. [CrossRef]

15. Jiménez-Crespo, M.A. The Internet in translation education: Two decades later. Transl. Interpret. Stud. 2015, 10, 271-282. [CrossRef]

16. Azubuike, O.B.; Adegboye, O.; Quadri, H. Who gets to learn in a pandemic? Exploring the digital divide in remote learning during the COVID-19 pandemic in Nigeria. Int. J. Educ. Res. Open 2020, 5, 100022. [CrossRef]

17. Cao, Y.; Kovachev, D.; Klamma, R.; Jarke, M.; Rynson Lau, W.H. Tagging diversity in personal learning environments. J. Comput. Educ. 2015, 2, 93-121. [CrossRef]

18. Lim, R.F.; Hsiung, B.; Hales, D.J. Lifelong learning: Skills and online resources. Acad. Psychiatry 2006, 30, 540-547. [CrossRef]

19. Washburn, C.; Saunders, K. Extension Disaster Education Network (EDEN): Preparing families for disaster. J. Fam. Consum. Sci. 2010, 102, 61-63.

20. Jaggi, R. Narratives of online education in India: Issues of equity, inclusion, and diversity. J. Child. Media 2020, 15, 55-59. [CrossRef]

21. Anderson, R.E. Gender and computers: Understanding the digital divide. J. Marriage Fam. 2004, 66, 542-543. [CrossRef]

22. Chia-Wen, T. The use of mobile technology and ubiquitous computing for universal access in online education. Univers. Access Inf. Soc. 2016, 15, 313-314. [CrossRef]

23. Savage, S.J.; Waldman, D. Broadband internet access, awareness, and use: Analysis of United States household data. Telecommun. Policy 2005, 29, 615-633. [CrossRef]

24. Szatmary, D. The internet, partnerships, and online education. Contin. High. Educ. Rev. 2000, 64, 43-46. 
25. Araque, J.C.; Maiden, R.P.; Bravo, N.; Estrada, I.; Evans, R.; Hubchik, K.; Kirby, K.; Reddy, M. Computer usage and access in low-income urban communities. Comput. Hum. Behav. 2013, 29, 1393-1401. [CrossRef]

26. Fei, P.; He, P. Comparison of the minimum subsistence guarantee system in Chinese city and country. J. US China Public Adm. 2007, 4, 11-20.

27. Li, Y.; Ranieri, M. Educational and social correlates of the digital divide for rural and urban children: A study on primary school students in a provincial city of China. Comput. Educ. 2013, 60, 197-209. [CrossRef]

28. Faziharudean, T.M.; Mitomo, H. Digital divide among public servants in Malaysia: Urban-rural differences in valuing the use of the Internet. Stud. Reg. Sci. 2006, 35, 837-849. [CrossRef]

29. Aduwa-Ogiegbaen, S.E.O.; Iyamu, E.O.S. Availability and utilization of classroom computers Across urban and rural schools in Southwestern Nigeria. Int. J. Inf. Commun. Technol. Educ. 2009, 5, 74-87. [CrossRef]

30. Hart, K.; Venter, J. Comparison of urban and rural dropout rates of distance students. Perspect. Educ. 2013, 31, 66-76.

31. Qiang, F.; Qiang, R. Educational inequality under China's rural-urban divide: The Hukou system and return to education. Environ. Plan. A Econ. Space 2010, 42, 592-610. [CrossRef]

32. Huang, X.; Dijst, M.; Weesep, J.V.; Zou, N. Residential mobility in China: Home ownership among rural-urban migrants after reform of the hukou registration system. J. Hous. Built Environ. 2014, 29, 615-636. [CrossRef]

33. Yang, Y.; Hu, X.; Qu, Q.; Lai, F.; Shi, Y.; Boswell, M.; Rozelle, S. Roots of tomorrow's digital divide: Documenting computer use and Internet access in China's elementary schools today. China World Econ. 2013, 21, 61-79. [CrossRef]

34. Kakwani, N.; Li, S.; Wang, X.; Zhu, M. Evaluating the effectiveness of the rural minimum living standard guarantee (Dibao) program in China-ScienceDirect. China Econ. Rev. 2019, 53, 1-14. [CrossRef]

35. Zhang, H. The minimum living standard guarantee system and citizenship cultivation among the poor in China. Asian J. Soc. Sci. 2017, 45, 483-506. [CrossRef]

36. Lei, J. Covering whoever is eligible? An exploratory study on the eligibility of the urban minimum living standard guarantee in China. Crit. Soc. Policy 2014, 34, 155-174. [CrossRef]

37. Gustafsson, B.; Li, S.; Sato, H. Data for studying earnings, the distribution of household income and poverty in China. China Econ. Rev. 2014, 30, 419-431. [CrossRef]

38. Luo, J.; Chen, Y.; He, H.; Gao, G. Hukou identity and fairness in the ultimatum game. Theory Decis. 2019, 87, 389-420. [CrossRef]

39. Zhu, Y. China's floating population and their settlement intention in the cities: Beyond the Hukou reform. Habitat Int. 2007, 31, 65-76. [CrossRef]

40. Long, C.; Han, J.; Yi, C. Does the effect of Internet use on Chinese citizens' psychological well-being differ based on their Hukou category? Int. J. Environ. Res. Public Health 2020, 17, 6680. [CrossRef]

41. Wu, X.; Treiman, D.J. The household registration system and social stratification in China: 1955-1996. Demography 2004, 41, 363-384. [CrossRef]

42. Baron, R.M.; Kenny, D.A. The moderator-mediator variable distinction in social psychological research: Conceptual, strategic, and statistical considerations. Chapman Hall 1986, 51, 1173-1182. [CrossRef]

43. Smith, A.D.; Rupp, W.T. Managerial implications of computer-based online/face-to-face business education: A case study. Online Inf. Rev. 2004, 28, 100-109. [CrossRef]

44. Reddy, B.; Jose, S.; Vaidehi, R. Of access and inclusivity: Digital divide in online education. Econ. Political Wkly. 2020, 55, 23-26.

45. Facer, K.; Selwyn, N. Towards a sociology of education and technology. In Contemporary Debates in the Sociology of Education; Brooks, R., McCormack, M., Bhopal, K., Eds.; Palgrave Macmillan: New York, NY, USA, 2013; pp. 218-235. 